\title{
Some Elements of Biologization in Crops Production on Radioactively Contaminated Areas
}

\section{Alexandr Dutov, Vladimir Rodionov, and Nina Belogurova}

Institute for Retraining and Advanced Training of Agribusiness Personnel, Belgorod State Agricultural University named after V. Gorin, Belgorod region, Belgorod district, Maisky, Russia

\section{Abstract}

The modern environmental and biological approaches to the selection of field agricultural crops for cultivation at contaminated areas are considered. It is established that the satiation of rotations with agricultural crops differed by potentially low capacity to accumulate ${ }^{13} \mathrm{Cs}$ can significantly extend the areal of radioactively contaminated lands use for the production of safe products. The influence of arbuscular mycorrhizal fungi on radiocaesium uptake by plants is analyzed. The ability of arbuscular mycorrhiza to modify significantly radiocaesium accumulation by agricultural crops is found.

Corresponding Author:

Alexandr Dutov

dutov_bsau@mail.ru

Received: 25 October 2019

Accepted: 15 November 2019

Published: 25 November 2019

Publishing services provided by

Knowledge E

(c) Alexandr Dutov et al. This article is distributed under the terms of the

Attribution License, which

permits unrestricted use and redistribution provided that the original author and source are credited

Selection and Peer-review under the responsibility of the AgroSMART 2019 Conference Committee.
Keywords: biologization of agriculture, radiocaesium, agricultural crops, radioactively contaminated areas, arbuscular mycorrhizal fungi, mycorrhizal colonization

\section{Introduction}

Nowadays the radiocaesium remains one from the most biologically significant pollutant that determines the degree of radiation risk for the population. The principal pathway of its intake to humans is the consumption of agricultural products produced in contaminated areas. This paradigm is confirmed by experience to overcome the consequences of the Chernobyl catastrophe in1986 and the accident at Fukushima NPP Fukushima in 2011 [1--3]. The agricultural activity under these conditions implies the implementation of complex anti-radiation agrochemical measures aimed at reducing population exposure by ensuring the production of radioecologically safe agricultural products [4--6].

Last years the significant attention is paid to the greening of agriculture, in particular environmental biotechnologies aimed at the combined use of certain plants species and soil microorganisms [7]. Among these microorganisms arbuscular mycorrhizal (AM) fungi are of particular importance, since about $90 \%$ of plants form symbiotic relationships with these fungi and create mycorrhizal associations [8]. Along with the preservation 
and improvement of soil fertility, the use of AM fungi significantly reduces the chemical load on the environment and the population, which is especially important in areas contaminated after nuclear and radiological incidents.

\section{Methods and Equipment}

The activity concentration of $137 \mathrm{Cs}$ and $134 \mathrm{Cs}$ in roots and shoots of studied plants was determined using gamma-spectrometer with semiconductor p-type coaxial high purity $\mathrm{HP}-\mathrm{Ge}$ detector with a relative efficiency of $15 \%$ and resolution of 2.5 at $1.33 \mathrm{MeV}$.

The plants were cultivated on the artificially prepared substrata spiked with 134Cs. The activity concentration of 134Cs in the soil was 77000 Bqkg-1. To evaluate the accumulation of radionuclides in crops at different radiocaesium concentrations the accumulation factor (AF, the ratio [Bqkg-1of plant air-dry weight / kBqm-2 in soil]) and transfer factor (TF, the ratio [Bqkg-1 of plant air-dry weight / Bqkg-1 in soil]) of radiocaesium from soil to plants were used.

The colonization levels of plants with AM fungi were determined using Nikon Eclipse 800 ( Japan) light microscope with a photographic system Nikon FDX-35. The plant roots were stained with a solution of $0.01 \%$ aniline blue and $80 \%$ lactic acid. The quantitative analysis of mycorrhizal colonization of plants with intraradical structures of AM fungi was carried out according to Trouvelot method [9], using a six-level colonization scale.

\section{Results and Discussion}

The environmental and biological approaches to the selection of crops in agriculture in contaminated areas are based on their potential ability to accumulate radionuclides. According to the data presented on Figure 1, the plant field crops can be divided into three groups according to their potential capacity to accumulate ${ }^{137} \mathrm{Cs}$.

The minimal ${ }^{137} \mathrm{Cs}$ accumulation in the harvest was found in case of corn. The radionuclide accumulation factor in grains of this plant species was $0.07\left(\mathrm{~Bq}^{\mathrm{k}} \cdot \mathrm{kg}^{-1}\right)$ / $\left(\mathrm{kBq} \cdot \mathrm{m}^{-2}\right)$. The maximum radiocaesium concentration within the group of grain cereals was in oat grains. The concentration of ${ }^{137} \mathrm{Cs}$ in oat grains was 5 times higher than that of corn

The group of plants with potentially low ability to accumulate ${ }^{137} \mathrm{Cs}$ also includes potatoes. The radiocaesium accumulation factor in its tubers is intermediate between spring wheat and barley, but is $71 \%$ higher than for corn. The group of groat cultures was characterized with higher potential accumulation of radiocaesium. Thus, the ${ }^{137} \mathrm{Cs}$ 
concentration in millet was nearly the same as in winter rye, but three times lower than in buckwheat (Fig. 1). However, the maximum accumulation of ${ }^{137} \mathrm{Cs}$ is typical for group of grain legumes. In particular, in pea plants the radiocaesium concentration was 13 times higher as compared to corn.

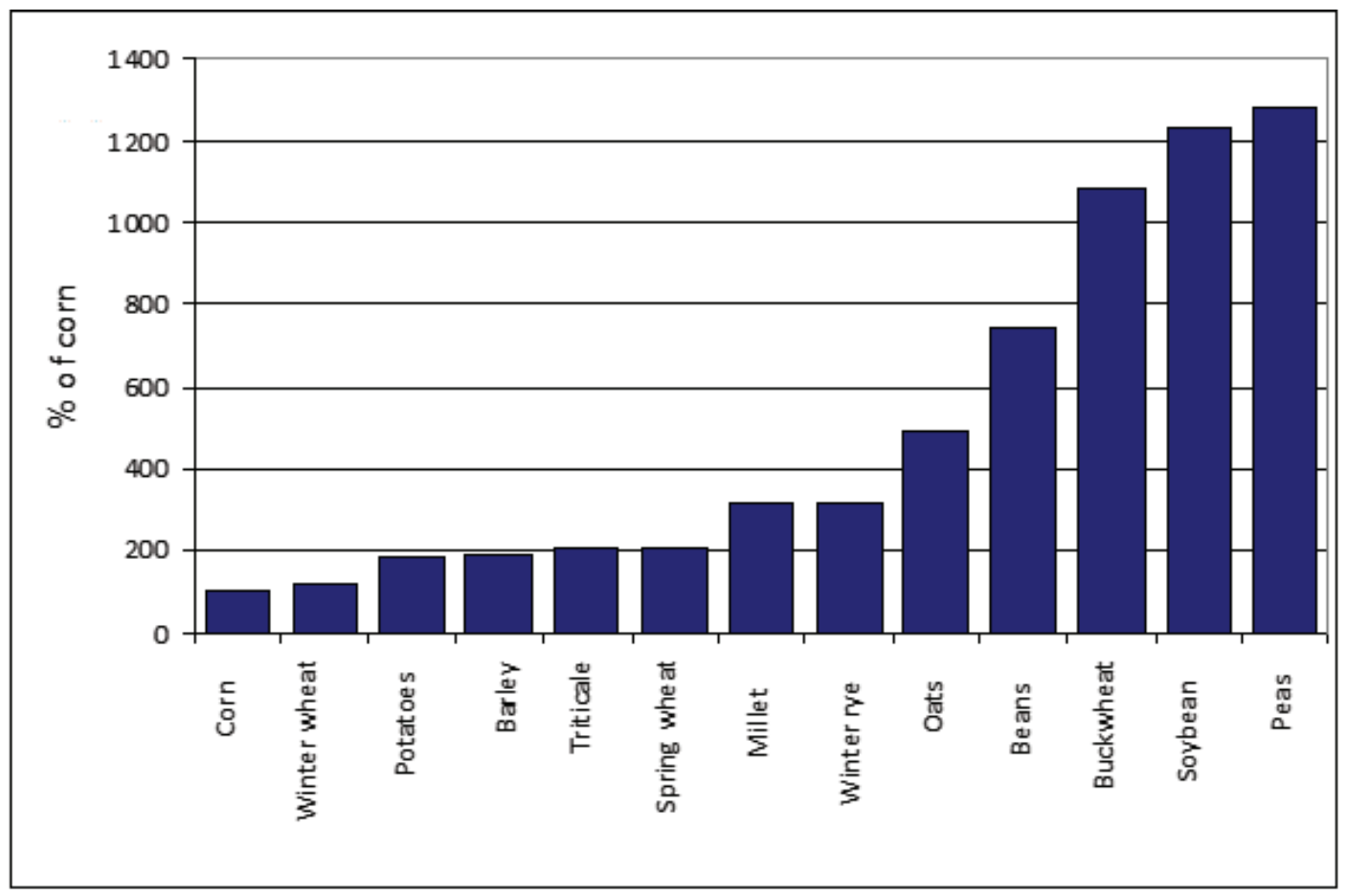

Figure 1: Relative accumulation of ${ }^{137} \mathrm{Cs}$ by field crops, \% of corn.

According to the above mentioned aspects, the use of selection and saturation of crop rotations differed with potentially low capacity to accumulate radiocaesium could extend significantly the areal of contaminated lands exploitation for the cultivation of agricultural production that meets the current hygienic standards.

To study the influence of arbuscular mycorrhizal (AM) fungi on the radiocaesium accumulation by agricultural crops in laboratory conditions alfalfa (Medicago truncatula) and sunflower (Helianthus annuus) plant species were selected. The AM fungus Glomus intraradices (strain BIO; company BIORIZE, Didjon, France) was used for plant inoculation. This species is widespread in a variety of soil types and shows high colonization ability in symbiosis with many plant species [10].

The obtained results demonstrate the ability of arbuscular mycorrhiza to modify significantly the accumulation of radiocaesium by plants. In particular, the inoculation with $A M$ fungus $G$. intraradices resulted in $52 \%$ decrease of ${ }^{134} \mathrm{Cs}$ transfer factor in above-ground parts of alfalfa as compared to non-mycorrhizal control. At the same time, the mycorrhizal M. truncatula plants accumulated $19 \%$ less of ${ }^{134} \mathrm{Cs}$ than mycorrhizal 
ones (Table 1). Thus, the presence of arbuscular mycorrhizal symbiosis led to $80 \%$ increase of the ratio between ${ }^{134} \mathrm{Cs}$ activity concentration in underground and aboveground parts of alfalfa, and consequently to reduction of the radionuclide transfer from plant root system to aboveground organs.

The opposite effect of arbuscular mycorrhiza impact was observed in sunflower, where almost tenfold rise of ${ }^{134} \mathrm{Cs}$ activity concentration was noticed in AM inoculated plants as compared to the control ones (from 0.50 to 4.92 in the root system and 0.34 to 3.19 in the above-ground organs). The mycorrhizal plants of this species demonstrated the hyperaccumulation ability for radiocaesium. During the three-month cultivation period they accumulated relatively large $(0.22--0.27 \%)$ of the radionuclide from the substrata.

The mechanisms which AM fungi use to retain radiocaesium and other radionuclides into their structures and limit or increase their income to the plants have not been studied in details. Nowadays two basic processes are known: 1) release of chemical compounds by AM fungus that convert pollutants in the soil into non-exchangeable forms, sometimes with pollutant fixation on the outer surface of the mycelium and 2) compartmentalization - the translocation of absorbed pollutant to organ where it can be better tolerated or in a subcellular compartment where it can be stored away from the cytoplasm [11].

The mycorrhizal plants of alfalfa and sunflower cultivated on substrata spiked with ${ }^{134} \mathrm{Cs}$ and "control" soil were characterized with significant levels of AM colonization (84--98\%). The colonization of plant root fragments was homogeneous, and intraradical structures of AM fungus $G$. intraradices formed Arum-type of mycorrhizae.
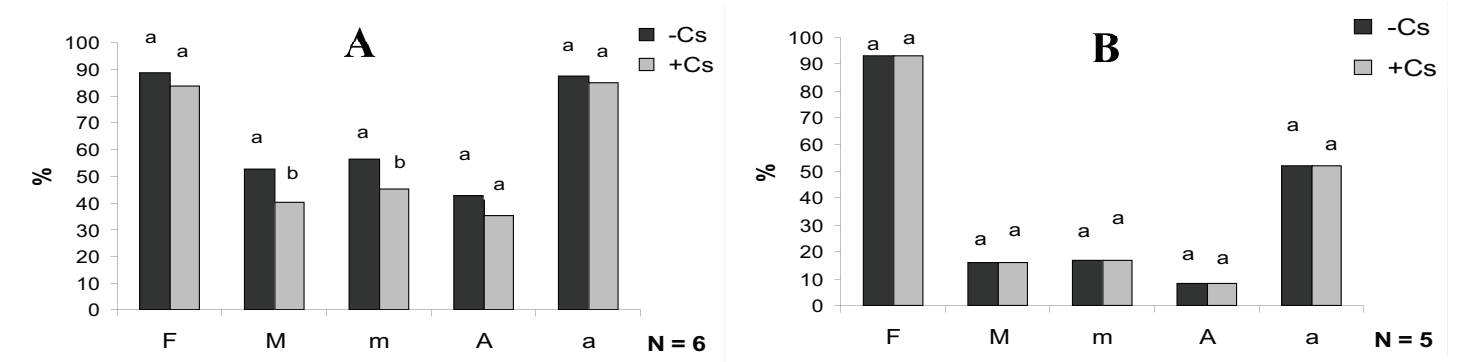

Figure 2: Arbuscular mycorrhizal colonization parameters (\%, medians) of Medicago truncatula (A) and Helianthus annuus (B) inoculated with Glomus intraradices: F\%, frequency of mycorrhiza; M\%, mycorrhizal colonization intensity for all roots; $\mathrm{m}(\%)$, mycorrhizal colonization intensity within individual mycorrhizal roots; $A \%$, arbuscule richness for all roots; $a \%$, arbuscule richness in root fragments where the arbuscules were present. Plants were cultivated on non-spiked substrata $(--\mathrm{Cs})$ and substrata spiked with ${ }^{134} \mathrm{Cs}(+\mathrm{Cs})$; the different letters above bars mean statistically significant differences $(p<0.05)$.

The high concentration of arbuscules in colonized roots of all plant species (52--89 $\%)$ indicates the effective functioning and good qualitative condition of mycorrhizae. 


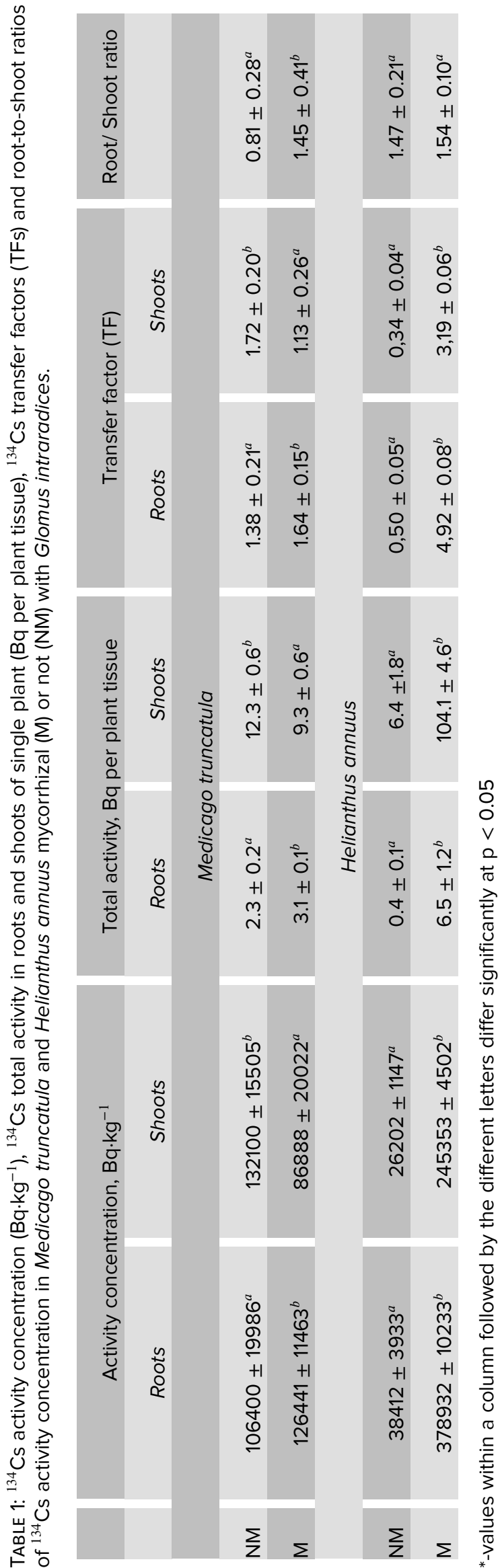


According to the data presented on Figure 2, the parameters of AM colonization of alfalfa roots were significantly higher than those of sunflower.

It should be noted that the presence of radiocaesium in soil did not affect the parameters of AM colonization of sunflower. At the same time it resulted in a certain decrease (10--12 \%) of mycorrhizal colonization intensity parameters ( $\mathrm{M}$ and $\mathrm{m}$ ) in case of alfalfa.

\section{Conclusion}

The environmental and biological approaches in agriculture in contaminated areas include the more efficient use of the potential ability of crops to accumulate radionuclides and the application of certain species of soil microorganisms. It results in reduction of chemical load on agro-ecosystems and contributes to the preservation and fertility of radioactively contaminated soils.

AM fungi demonstrate the capacity to transform and immobilize radiocaesium in their structures and limit its uptake by certain plant species. The efficiency of mycorrhizae in the process of radiocaesium transfer is not determined by $\mathrm{AM}$ colonization degree and demonstrates the dependence of radionuclide transfer factors on the biological features of plants.

The potential use of AM fungi for cultivation of certain crops in radioactively contaminated soils require more comprehensive study in order to reduce the chemical load on the environment by minimizing the introduction of fertilizers and greening of agriculture.

\section{Acknowledgement}

The authors would like express gratitude to their colleague for their contribution and support to the research. They are also grateful to all the reviewers who gave their valuable inputs to the manuscript and helped in completing the paper.

\section{Conflict of Interest}

The authors have no conflict of interest to declare. 


\section{References}

[1] 30 years of the Chernobyl accident. Results and prospects of overcoming its consequences in Russia. 1986---2016. (Russian national report, 2016, 202 p), under the general. ed. V.A. Puchkova, L.A. Bolshova. Moscow: Academ-Print.

[2] Hirose, K. (2012). Fukushima Dai-ichi nuclear power plant accident: summary of regional radioactive deposition monitoring results, Journal Environ. Radioact, vol. 111, pp. 13--17.

[3] Dutov, A.I., Bulygin, S.Yu., Lisetskiy, F.N. (2015). Chernobyl resettlement zone: radiation and environmental aspects of the prospective agricultural use of the territory. Scientific Bulletin of the Belgorod State University. Natural Sciences, no. 9(206), iss. 31, pp. 186--191.

[4] Prister, B.S. (2008). Problems of agricultural radioecology and radiobiology during environmental pollution by young mixtures of nuclear fission products. Chernobyl, K.: Book, 320 p.

[5] Bondar, O.I., Dutov, O.I., Mashkov, O.A. (2013). Innovation and information before criticality of critical products in the world, regions, foreign labor disaster. Zborniy disaster. sciences. prts Institute of Model Modeling problems in power-engineering of NAS, VIP, no. 69, pp. 119--130.

[6] Dutov, O.I. (2012). It is advisable to go to the regional vikoristan radio-active bad land (at the application avarii at Chornobilsky AES). Agrokhimiya i Gruznozavstvo. Midtheme thematic science zbirnik. Вип. 77. Kharkiv: NSC "IGA im. IT. Sokolovskogo", pp. 38--43.

[7] Entry, J.A., Astrud, L.S., Reeves, M. (1999). Accumulation of 137Cs and 90Sr from contaminated soil by three grass species inoculated with mycorrhizal fungi. Environ. Pollut., vol. 104, pp. 449--457.

[8] Smith, S.E., Read, D.J. (1997). Mycorrhizal Symbiosis. San Diego: Academic Press, $312 \mathrm{p}$.

[9] Trouvelot, A., Kough, J.L., Gianinazzi-Pearson, V. Mesure du taux de mycorhization VA d'un système radiculaire. Recherche de méthodes d'estimation ayant une signification fonctionnelle. In: Gianinazzi-Pearson, V., Gianinazzi, S. (eds.). Physiological and Genetical Aspects of Mycorrhizae. Paris: INRA Press, pp. 217--221.

[10] Kripka, G.V., Sorochinsky, B.V. (2003). Otrimannya and viprobuvannya inokulyativ arbuscular mycorrhizal fungi with the method of modifikatsiya poglinannya radionuklidiv roslinami. Zb. scientific research Institute of Nuclear Research, no. 2(10), pp. 80--84. 
[11] Meharg, A.A. (2003). The mechanistic basis of interactions between mycorrhizal associations and toxic metal cations. Mycol. Res., vol. 107, pp. 1253--1265. 